THE INTERNATIONAL

REVIEW OF RESEARCH IN

OPEN AND DISTANCE LEARNING

\title{
Investigating Instructional Strategies for Using Social Media in Formal and Informal Learning
}
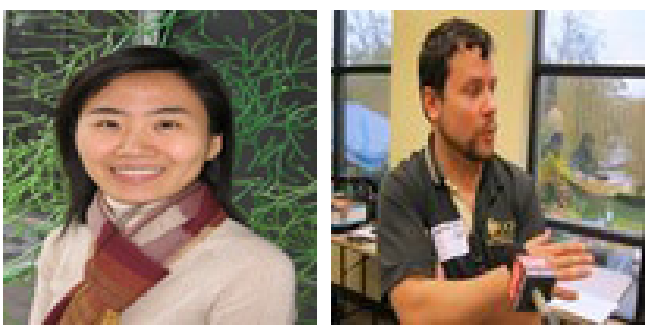

Baiyun Chen and Thomas Bryer University of Central Florida, USA

\section{Abstract}

Despite the high popularity of personal use of online social media, a low percentage of students and instructors use them for educational purposes. This qualitative study explores the use of social media among faculty in the discipline of public administration in the United States. Eight instructors participated in telephone interviews about their experiences and perceptions of using social media for teaching and learning. Instructors perceive that informal learning using social media could be facilitated by instructors and integrated into formal learning environments for enriched discussions, increased engagement, and broad connections. This study provides qualitative empirical support for social learning theories while offering strategies for and examples of how social media can be used to connect formal and informal learning.

Keywords: Social media; qualitative study; public administration; instructional strategy; formal learning; informal learning; social networking

\section{Introduction}

The use of social media has surged globally in recent years. Based on individual companies' statistics in July 2011, Facebook passed 750 million users (2011); LinkedIn had over 100 million members (2011); Twitter hit over 177 million tweets per day (2011); YouTube reached three billion views every day (2011). Social media are infiltrating the educational arena. The online social networks are increasingly being used not only by college students, but also by instructors for different reasons (Mazer, Murphy, \& Simonds, 2007; 2009). Hence, understanding the way individuals behave on such sites is a potentially valuable source of information for educators and researchers. 
Social media has been defined in different ways. For this study, we use the definition advanced by Bryer and Zavatarro (2011, p. 327): "Social media are technologies that facilitate social interaction, make possible collaboration, and enable deliberation across stakeholders. These technologies include blogs, wikis, media (audio, photo, video, text) sharing tools, networking platforms (including Facebook), and virtual worlds." The technologies of particular interest in this study are those that are web-mediated, thus falling within the realm of read/write collaborative Web 2.0 tools (Bryer \& Zavatarro, 2011). These contrast with media tools that have social features, but which may not connect individuals or groups through the Internet (e.g., response system technology, Rishel 2011).

The present study investigates how educators use social media to connect formal and informal learning and allow students to connect in new and meaningful ways. Our research focuses on understanding the use of social media tools among higher education faculty, strategies they use to integrate social media in formal learning, concerns they have, and their strategies to mitigate those concerns. The findings of this study will expand our knowledge about the use of social media and offer strategies for and examples of how these technologies can be used to connect formal and informal learning.

\section{Literature Review}

Two streams of literature are considered here. First is the history and development of social learning theories. Second is the distinction between formal and informal learning and the potential role of social media to connect both learning environments. Existing research and commentary regarding the efficacy of social media for education is also discussed below.

\section{Social Learning Theories}

The notion of social learning can be traced back to the theory of social constructivism in the 1960s (Vygotsky, 1978). The basic principle is that students learn most effectively by engaging in carefully selected collaborative problem-solving activities, under the close supervision of instructors (Vygotsky, 1978). Collaboration is the most important characteristic of social learning. While instructors help to facilitate group interactions, students have the autonomy to self-select what they need to learn to gain a better understanding of the problem.

A large body of critical analyses and research later concurred that learning is not an individual acquisition activity, but a social discourse (Hanson \& Sinclair, 2008; Jonassen, Howland, Moore, \& Marra, 2003; Lave \& Wenger, 1991). Many studies strongly suggest that collaborative learning has proven to be more effective than individualistic learning in contributing to motivation, in raising achievement, and in producing positive social outcomes ( Johnson, Johnson, \& Stanne, 2000; Slavin, 1995; Snowman, McCown, \& Biehler, 2009).

In the new digital age, Siemens (2004; 2005) and Downes (2007) proposed the connectivism theory, where social learning is integrated with social media technologies. In the world of social media proliferation, learning is not an internal, individualistic activity. Rather, learners gather information from connecting to others' knowledge using Wikipedia, Twit- 
ter, RSS, and other similar platforms. One of the principles of connectivism is that capacity to learn is more critical than what is currently known (Siemens, 2004). The responsibility of a teacher is not just to define, generate, or assign content, but it is to help learners build learning paths and make connections with existing and new knowledge resources (Anderson \& Dron, 2011). Social learning theories, especially connectivism, provide insights on the roles of educators in this social networked environment.

\section{Formal and informal learning.}

Banks and his research team (2007) studied learning in formal and informal environments. Their findings indicate that formal learning is only a small fraction of the lifelong experience of human learning: The role of formal learning is about $19 \%$ in the first through twelfth grades, and the percentage is reduced to $8 \%$ in undergraduate years and $5 \%$ in graduate years. As students progress from high school to college and graduate schools, the role of informal learning becomes more and more important because learning can happen anywhere at any time. Learners acquire knowledge as a function of interactions between connected partners. The interactions allow learners to raise their connections with content and peernetworks. Social connections and networks are changing the ways we think about knowledge and learning and the ways we organize work and ideas.

Unfortunately, social networks have little or no integration into formal learning environments. The course management system (CMS), such as Blackboard, Sakai, and Moodle, is the most widely used learning technology in traditional higher educational settings. The conventional CMS environment provides limited opportunities for online learners to participate in online interactions, such as discussions and chats. These interaction activities are normally restricted to one class in one semester. Despite the fact that some social media features have begun to be integrated into newer versions of CMS, these features still cannot be fully implemented due to security or privacy restrictions. For example, CMS wikis cannot be shared with viewers outside of the institutions; learning portfolios cannot be maintained over multiple semesters. The connectivity and openness are lost in the present formal learning environment given the lack of access to external social opportunities.

Uses of social media as learning tools could possibly connect informal learning to the formal learning environment. For instance, third-party social media tools, such as WordPress, Wikipedia, and LinkedIn, can include members outside the class beyond the one-semester time duration and connect learners with communities, experts in the field, and peers across the world. It also provides engaging channels to facilitate student-student, studentinstructor, and student-content interactions in multimedia formats. This environment of involvement and creation potentially allows users to become more engaged in the learning process, and it entices users to collaborate on projects in real-world situations. Social media technologies that allow students to connect to educational contexts in new and meaningful ways beyond the traditional classroom environment have the potential to blur the line between formal and informal learning. The goal of this article is to investigate how educators can make this change happen. 


\section{Existing Research}

As social media is becoming increasingly ubiquitous to millennium learners, educators see the potential benefits of using these tools for academic purposes (Hughes, 2009; Nellison, 2007). Unfortunately, there is limited research on how social media impacts students and, in particular, how it influences students' learning experience (Hew, 2011; Mix, 2010). One of the common themes in previous research is that students use social media for personal reasons, but rarely for educational or learning purposes (Hew, 2011). Based on the 2009 and 2010 data from the EDUCAUSE Center for Applied Research (Caruso, Smith, \& Salaway, 2009; Smith \& Borreson, 2010), over 90\% of students responded that they used social networking services, such as Facebook, MySpace, Bebo, and LinkedIn. However, less than $30 \%$ of the participants reported using them in a course during the quarter or semester of the annual surveys. Uses of other social media sites, such as video sharing, blogs and wikis, follow the same pattern. EDUCAUSE (Smith \& Borreson, 2010) reported that only about $30 \%$ of their surveyed students used web-based word processor, spreadsheet, presentation, and wiki tools in courses. Even fewer students reported using technologies, such as video/photo-sharing sites, calendars, citation tools, blogs, social bookmarking tools, and online virtual worlds for classes. The limited education-related activities on social media platforms include creating study groups and other interactions with classmates without the knowledge of the instructor, "post-hoc" critiquing of learning experiences and events, reading web resources with little evidence of critical inquiry or analytical awareness, and file sharing, gaming, and brief communicating (Selwyn, 2009).

The use of social media in teaching by instructors is even scarcer. The Faculty Survey of Student Engagement (FSSE, 2010) surveyed 4,600 faculty members from 50 U.S. colleges and universities in 2009 and found that over 80\% of the surveyed faculty did not know or never used social media technologies such as blogs, wikis, Google docs, video conferencing, video games, or virtual worlds. The only technology FSSE reported that faculty use extensively was the CMS. The national survey findings (2010) suggested that most instructors continue to teach using traditional lecture-based instruction. Empirical research is lacking in terms of what strategies instructors used for teaching with social media.

Despite the limited usage of social media in the academic world, research has supported connectivism theory and found benefits in using social media by instructors if the technology is adopted for teaching ( Mazer et al., 2007; 2009). Mazer et al. examined the effects of an instructor's self-disclosure via Facebook on her credibility as perceived by undergraduate students. Results showed that students tend to attribute higher perceived levels of instructor credibility to an instructor who willingly disclosed more information on Facebook than one who did not. More research needs to be conducted on instructor presence and social media strategies.

The literature identified concerns for using social media as a teaching and learning tool, such as its negative effects on academic performance. One study addressed the relationship between social media usage and academic performance (Kirschner \& Karpinski, 2010). The researchers surveyed 219 university students and found that Facebook users had signifi- 
cantly lower GPAs compared to non-users. This study did not infer a direct causal relationship and asked researchers to conduct further research on the impacts of social media on academic performance. The question is, if more instructors could facilitate social media activities based on the connectivist pedagogy to alter how the technologies are used, could social media be a beneficial learning tool? The gap between the theory and the lack of research to support students' networked learning indicates that researchers should consider how students and instructors can be encouraged to use these technologies and how to infuse social practices into learning activities using sound pedagogical practices.

There are discussions in the literature around the ethical issues of using social media in academic environments. Students' privacy and security issues are the primary concern (Foulger, Ewbank, Kay, Popp, \& Carter, 2009). The Family Educational Rights \& Privacy Act (FERPA) requires that student education records be protected. However, a class discussion on social media might reveal students' identification to the public. Moreover, some students are not aware that their posted information on social media is publicly available. A piece of personal information or a picture on the Web might lead to issues of identity theft or prevent them from future career opportunities. This study investigates this issue further.

\section{Research Questions}

This paper examines the pedagogical practices of using social media for teaching and learning based on qualitative data gathered from semistructured interviews with public administration faculty from institutions in the United States, who have already integrated social media in their class. The guiding questions for this study are as follows:

- RQ I: What social media tools do public administration faculty use and why?

- RQ II: What instructional strategies do public administration faculty use to integrate social media in formal learning?

- RQ III: What concerns do faculty have regarding the use of social media for teaching and what strategies do they have for mitigating these concerns?

\section{Population}

The study was designed as an exploratory analysis of current practices, concerns, and perceptions of public administration faculty regarding the use of social media in teaching. The social and multidisciplinary characteristics of social media are the reason to focus on the field of public administration. Public administration can be defined as "the intersection of multiple disciplines and sub-disciplines, joined together in the common interest of supporting or developing community, region, state, country, or world" (Bryer \& Chen, 2010, p. 241). Increasingly, public administration is recognized as a field well suited to forge collaboration across businesses, nonprofit organizations, government agencies, faith organizations, and active citizens. 


\section{Methods}

Given that there is relatively limited research on pedagogies of using social media, we used qualitative methods to explore the research questions through rich descriptions and explanations. The qualitative data reported in this article were collected as part of a larger research project, which surveyed a national sample of public administration faculty $(N=$ 57 to investigate the educational use of social media technology. The survey covered preliminary data on the types of social media sites, features of sites used, the interaction activities and assessment strategies used, motivation and concerns for faculty, and demographic questions. The survey findings were reported in Bryer and Chen (2010).

Interviews were semistructured to ensure that all participants were asked questions regarding their interaction and assessment strategies and motivations and concerns and to encourage them to raise other issues they felt relevant to the research. The interview questions are included in the Appendix.

\section{Data Collection}

Requests for participation in the study were emailed to the chairs/directors of all public administration departments or degree programs at institutions with accredited Masters in Public Administration (MPA) degrees in September 2009. A total of 57 faculty members from 28 universities across the United States voluntarily completed the initial survey.

Additionally, eight interviews were conducted by telephone in March 2010, averaging 30 minutes. Based on the theoretical sampling method (Glaser \& Strauss, 1967), we chose to interview participants to ensure a good mix of each of our theoretical categories: school location, ranking, and types of social media used. The interviewees are from five universities and one college, which are located in the north, east, south, and central United States. They hold six academic rankings, including department chair (tenured associate or full professor), professor, associate professor, assistant professor, and instructor. The interview questions focus on social media strategies in classes, especially strategies to engage students, assessment strategies, and measures to mitigate general concerns about using social media.

\section{Data Analysis}

All phone interviews were audio-recorded, transcribed, and checked for accuracy by the researchers. Google Doc spreadsheet tables were used for coding between the two researchers. The transcripts were analyzed and coded, and statements were classified into themes to answer the research questions. The constant comparison technique was used as the coding method (Glaser \& Strauss, 1967). All qualitative data were reviewed multiple times and open-coded to produce an initial code list until analysis reached theoretical saturation. Using this initial code list, the data were then selectively coded in terms of categories, identified with the initial code list directly related to social media tools, activities, assessments, benefits, concerns, and best practices. A total of 114 codes were generated based on the interview transcripts. One coder conducted the full analysis; a random selection of statements was later re-coded by a second coder, which produced full agreement on category 
assignments.

\section{Results}

\section{RQ I: What Social Media Tools do Public Administration Fac- ulty Use and Why?}

All interviewees used social media, either for personal, academic, research, or professional purposes. The most popular services were Facebook and LinkedIn. The majority of them used Facebook for personal communication and LinkedIn for professional connections. Some other services mentioned in the interviews include course management systems (CMS) (e.g., Blackboard), blog services (e.g., Blogger.com), wiki services (e.g., PBWorks), audio/video conferencing tools (e.g., Elluminate), virtual world services (e.g., Second Life), and screencast tools (e.g., Jing). Among all tools, CMSs were the most frequently used tool for teaching.

All of them used social media for personal benefits "at leisure" because the technologies are user-friendly. Their attitudes towards using social media for teaching were mixed. Some individuals did not see any academic benefits at all or considered social media to only be relevant to "lower-level undergraduate classes."

Most participants, however, saw added learning advantages and strongly encouraged students to participate for the benefit of creativity and social connections. Seven out of eight participants discussed the benefits. Ease of use is at the top of the list. Participants perceived students to be familiar with social media technologies. Faculty perceived that checking out Facebook and reading blogs were part of students' daily life. Social media were also perceived to provide added learning benefits. For instance, faculty believed that students could exercise their creativity with images, audios, and video mashups. One respondent observed that using multiple tools in an integrated fashion can help students firm up their understanding, noting that he promoted "writing analytical blogs, publishing informed and thoughtful commentary on blog assignments and posing new questions in various threads to help integrate material/concepts/etc."

Additionally, a number of participants discussed the relevance of using social media in the field of public administration. In terms of course content, they used these technologies to demonstrate concepts of "information transparency" and "citizen participation" in the public policy arena. Some instructors used online videos from YouTube and case studies from wiki pages to discuss change theory and convey concepts about information policy. One participant offered that "in my Public Information Management course, I cover the topic of social networking and how it is being used by government and non-profits." Thus, using the networking tools directly serve as an experiential exercise.

More importantly, students could benefit from internship and job opportunities through social networks. One instructor mentioned that 25 to $30 \%$ of their graduates were on Face- 
book and LinkedIn, and most of them were working in the local government. She is not alone in helping students take advantage of social capital. Five other interviewees strongly encouraged their students to establish social connections with alumni and community professionals via LinkedIn or other networking platforms. One participant cited the use of Ning by the MPA student association for promoting job opportunities.

\section{RQ II: What Instructional Strategies do Public Administration Faculty Use to Integrate Social Media in Formal Learning?}

\section{Instructional activities.}

Discussions and collaborations were the strategies that most participants mentioned. These participants took advantage of the Web 2.0 technologies to interact with students, help them with job seeking, facilitate group projects, organize student association networks, and promote their courses, programs, and conferences. They facilitated a strong sense of community and encouraged collective intelligence by creating social networks around academic topics or connecting students with alumni, outside communities, and experts around the world. For example, one participant advised students to join professional organizations on social media, such as the LinkedIn group of the National Academy of Public Administration. Some participants believed that social media is the extended classroom for students where they can learn from real-life events and professionals in the field.

Moreover, online social networks are convenient ways for faculty and students to keep up with their professional connections. Five out of eight interviewees maintained an active LinkedIn profile to connect with friends and former students in the profession, discuss career development, maintain their professional organization membership, and expand their consulting businesses. They also encouraged their students to do the same.

Participants successfully integrated social media, such as videos and case study materials, as part of their instruction in classes. However, the interaction features were not fully taken advantage of by our participants. Most of them heavily relied on the discussion and chat tools inside the CMS for student-student, student-content, and student-instructor interactions.

Our participants were interested in using social media in teaching. Unfortunately, not everybody was successful. One interviewee tried to use a class blog to engage students for one semester. The blog activity was optional and all postings needed to be approved by the instructor before publishing. Such strict requirements resulted in poor student participation. The instructor decided to give up the blog activity for the next semester. This case indicates that social media participation is informal and unstructured, which contradicts the orderly and organized flow of regular classroom teaching.

Another interviewee shared her success stories with us. She integrated LinkedIn in her class. This was a required assignment but students were not graded directly based on their activities on LinkedIn. Instead, they were graded on their critical reflections from their 
discussions with alumni. In this case, students were provided with a learning goal, but their interactions on LinkedIn were largely based on their own interests instead of the instructor's requirements.

Interviewees also had success with social media activities outside of class. For instance, they maintained and shared learning content, such as just-in-time news articles and videos, and facilitated noncredit, extracurricular discussions amongst students and a network of friends, associates, and colleagues. One common theme is that the focus of these activities is learners' personal interests and preferences, rather than institutional or instructors' requirements. Our participants' experience indicates that the key to successfully using social media for teaching is trying not to reshape the informal interactions but to "democratize" the classroom by empowering students to choose how and with whom to forge relationships. Their experience suggests that learning on social media is informal, conversational, and driven by users' interests.

\section{Assessments.}

The interviewees were probed about their assessment strategies regarding their social media activities. Most participants did not have an assessment strategy specifically designed for using social media. They felt that social learning should be optional, not required in classes. If some students chose not to complete the activities on social media due to personal reasons, they should not be punished for nonparticipation.

Among all the interviewees, two listed their social media activity in the course syllabi as a required assignment. Students were informed in the syllabi that they would need to use blogs, wikis, or online social networks in the classes as part of the course assignments. Both participants reviewed students' postings. One interviewee awarded participation credits based on students' blog postings. The other interviewee, as described above, required students to summarize and reflect on their assigned LinkedIn activities and then post their reflections as discussion postings inside their university CMS. She did not grade students' social media activities directly due to FERPA requirements and school policies, which do not allow any grading outside university systems. Instead, she graded students' reflections on their LinkedIn activities in the CMS using an online discussion rubric. The rubric criteria included clarity, comprehension, original thinking, and writing. None of the criteria were designed to directly guide students on their LinkedIn activities.

Activities on social media are largely informal, open, and self-regulated, at least as reported by our interviewees. Integrating informal learning on social media into formal educational environments brings a challenge to evaluation. What is the best way in which to evaluate students' network building and self-exploration on social media? Our participants indirectly evaluated students' social learning activities. They did not use the conventional fixed-criteria assessments, such as tests or quizzes. Instead, they integrated social media to supplement and reinforce classroom teaching using formative assessment strategies, such as rubrics, portfolios, and reflections. According to the U.S. Department of Education (2010), formative assessment is normally carried out by either the instructor or the 
students throughout the learning process to diagnose and aid the condition of learning and instruction in the form of feedback and reflection. It is generally conducted to facilitate learning, not necessarily for grading purposes. For example, a student can post questions on personal career goals in the discussions area on LinkedIn. He might get feedback from not just the instructor, but also peers, alumni, and professionals in the community. The feedback information is not evaluative, but diagnostic. It might augment, concur, or conflict with the student's ideas and facilitate his or her subsequent learning. Eventually, instructors could evaluate students' learning progress by reviewing his or her reflections on what they have gained through networked learning.

\section{RQ III: What Concerns do Faculty have Regarding the Use of Social Media for Teaching and What Strategies do They Have for Mitigating these Concerns?}

The top-rated concerns are cyber-security and privacy issues. Faculty were concerned about their professional identity. Two participants mentioned RateMyProfessor.com in the interviews and feared that their presence on the Web might damage their professional reputation. The Internet is such an open environment that nobody can control what others might post. Besides, participants were also concerned about students posting inappropriate content online that might pose a danger to their own future career development. One respondent observed that "students do not perceive these as learning tools, therefore, they do not approach them or use them in a way that will facilitate learning." The tools themselves may be more identified with personal entertainment or interaction, and, thus, not be used appropriately for learning.

Ethical issues are the next concern for our participants, especially for those who are not in a leadership position. Such issues include cyberbullying, marginalizing students, and being unfair because of befriending one student over another. A number of the interviewees claimed that to avoid potential student-instructor relationship issues, they did not friend their students until they graduated. One respondent went further than that, indicating that "many of us have grave concerns about security and identity theft associated with social networking sites. I have removed my personal profile from Facebook, and use LinkedIn only with trusted adult business contacts."

Student and faculty support is the key to success using social media for education, according to our interviewees. One participant stated that all students in her program joined LinkedIn. Her students benefited enormously from social networking activities. Her program provided students with strong support services, such as free training sessions from the IT unit, library, and digital media specialists. The IT staff coached students if they had any difficulties using technologies for learning. The librarians also regularly delivered sessions on what should or should not be revealed on social media. Since students were using online social networks extensively in their program, other instructors in the program started to adopt this technology more willingly. The other participants also mentioned the importance of student training. Not all students are comfortable with new technologies. 
Even if they know how to use technologies for entertainment, the majority of them still need guidance on how these technologies could assist their learning process. Additionally, one respondent was concerned about distractions present through social media, observing that "the information that would come from social networking has a poor signal to noise ratio. It's easier to control through traditional assignments (readings, etc.) the feed of information I want students to have."

Time constraints and technology barriers are big concerns among senior faculty. Junior faculty were interested in learning new technologies, but workload and productivity also prevented them from exploring new tools for teaching. Our interviewees expressed a strong need for faculty support in terms of adopting new technologies. Five participants pointed out that they could not download or install any new software on their work computers. They heavily relied on the technical staff, and their university policies did not appreciate innovations. They would like to have access to new technologies and learn more about innovative ways of using them, such as best practices and pitfalls. They looked forward to their institutions embracing innovations. Our participants perceived that there was a need for crafting and implementing clearly stated institutional policies on the use of social media. Only one out of eight participants was aware of a social media policy in their institution. More instructors would be willing to try to integrate new technologies in teaching but only if they knew that they were supported and their rights were protected by their institutions.

\section{Discussion}

This study indicates that educators utilize social media as an instructional medium to blend informal learning into formal learning environments within the public administration discipline. Social media provides them with the ability to break the limitation of course management systems, enables innovative and collaborative interactions, connects textbook knowledge to real-world problems, and facilitates personalized constructive learning. However, respondents also observed pitfalls or challenges, such as privacy concerns for faculty and students and helping students use the tools for learning, rather than entertainment or personal interactions. This discussion section uses the observations from study participants and expands further to suggest areas for future development and research.

Social media and networking technologies have significant potential to recreate the learning environment between student and teacher. Learning can be experienced as a uniquely social enterprise; course content can be co-created by a community of learners, where the instructor is a learner along with students. The role of instructor might then transform to become as much facilitator as subject matter expert. As one respondent noted, such role transformation can allow greater interaction across the teacher-student divide: "Students are more engaged with the professor...thus, appear to be more engaged with the materials."

These technologies, however, may not be implemented in their most pure form to take advantage of their full potential. The concerns expressed by faculty-namely concerns of privacy and student-teacher relationships-may alter the social landscape to prevent possible 
desired learning outcomes from being achieved. This dynamic can be understood through Fountain's (2001) technology enactment framework. Writing about how government agencies adopt and adapt e-technologies, Fountain observed that there is an important distinction between objective and enacted technologies. Objective technologies are the tools available that might directly be applied in the practice of teaching and learning (e.g., Facebook, Wikispace, YouTube, Ning). Enacted technologies are the same tools altered, based on institutional rules and organizational culture. What is enacted, thus, may be less than what is possible given the optimum or full use of the technologies. Learning outcomes that are possible in social environments may not be realized if the social dimensions of the objective technologies are not fully enacted.

Continuing development of social networking and other collaborative tools and increased opportunities for interaction will require new ways to measure academic progress in real time. Using traditional formal learning assessments to evaluate the social learning process is difficult, especially if the learning happens outside the classroom in an informal learning environment. If educators make use of the informal learning that occurs on social media and networking services, it is possible that the achievement gap between marginalized students and mainstream students can be reduced. Conversely, as study respondents observed, using these social tools in the learning process may lead to more distractions, and, thus, reduce student achievement. Further testing is needed on this important question of impacts of social media on academic performance. Future research can also explore the effects of using rubrics for social media use on learning outcomes and can include experiments to determine the best facilitation and assessment strategies for social learning.

The cultural norms that create a separation between teacher and student represent one filter that can drive a wedge between objective and enacted social media and networking technologies. Teachers, who have reservations about sharing their full "personal" selves, may disadvantage their students by diminishing the roots of their passions in the subject matter being taught (Palmer, 2007). Faculty who address this cultural norm by creating separate social media identities for their students than those for friends and family fall into this trap, as do faculty who refuse to "friend" current students at all. Some respondents in this study participated in both activities. Splitting oneself into personal, professional, and other categories diminishes the full social potential of technologies that thrive based on a willingness to be transparent about one's whole self. The enacted technology, then, is less than social and, thus, less likely to generate desired learning outcomes.

To achieve possible learning outcomes, capacity building and training is necessary for faculty, so that they can understand the theory behind social learning and the limitations that are created through the erection of a wall between teacher and students. Similarly, university rules that permit or do not permit the use of social media for teaching need to be examined to ensure such rules are not artificially constraining the pure adoption of objective social technologies. This call for institutional support is consistent with findings from this study. Interviewees expressed a strong need for faculty support in terms of adopting new technologies. They would like to have access to technologies and learn more about new ways of using them, such as best practices and pitfalls. They looked forward to their institutions 
embracing innovations. There is, ultimately, a need for crafting and implementing clearly stated institutional policies on the use of social media in the educational environment.

\section{Limitations}

There are several limitations that should be acknowledged in this qualitative research method and sample. One major limitation is the self-selection bias as participants volunteered for the study. Even though our participants come from a variety of academic positions and locations in the U.S., those that volunteered might be biased toward a more positive outlook. Also, the data only include faculty members in departments of public administration in the United States. The findings shed light on usage of social media in teaching in one discipline but cannot be generalized to other areas of higher education. Future research could focus on educators in other disciplines and possibly from other countries.

\section{Conclusion}

One of the central questions of interest in this study is how to use social media to facilitate student learning. The experience of the participants suggests strategies to integrate these technologies, not just in formal in-class environments, but, more importantly, to encourage social and active learning that is learner-centered and informal. If informal social networks are facilitated and agenda-driven, learning can be achieved. Is the learning superior to traditional content-centered education? Future research needs to be conducted on this question. It seems safe to suggest, though, that the publicly open social media sites provide students with access to more information and experiences than they would get in a closed environment alone. If properly facilitated and framed, such expanded exposures can benefit student learning by creating more connections across boundaries and over time. Though social media are informal and open, it is possible to learn what works from current practices in designing social media spaces for learning. Each of these practices can be established through experimental or other research design to gain better understanding of what works and in what contexts. The following are some of the current practices drawn from this study:

- Use social media as tools to facilitate informal discussions and collaborations with clear instructional goals.

- Understand that the focus of social media activity for some faculty is learners' personal interests and preferences, rather than institutional or instructors' requirements, evidenced by faculty, who reported both opportunities and concerns regarding their perceived obstacles to students using social media for learning purposes.

- Evaluate students' reflections on their learning via social media in the form of formative assessment.

- Use social media as an optional tool inside and outside classes. Provide students with alternative assignments if they choose not to participate.

- Educate students about the security and privacy issues of posting personal information 
online.

- Implement institutional policies on the use of social media in the educational environment in light of security/privacy issues, as well as faculty and student support.

- The use of social media in higher education teaching is an emergent area for study.

As discussed in the literature review, much scholarly research needs to be conducted, and, perhaps more importantly, individual experimentation is needed to understand what works, how, and in what circumstances. We close, then, with a call to the public administration discipline, but also to other areas, for study and experimentation. Importantly, we call for institutional changes that can facilitate and indeed encourage experimentation by faculty members, who wish to determine the efficacy of social media tools for teaching. Institutional changes might include resources for training and for technology acquisition. They might include opportunities for controlled experimental research to test different tools and technologies and their efficacy in teaching and learning. Last, they might include the granting of flexibility to faculty members, who wish to test new tools and technologies on their office computers and for interacting with students in new, boundary-spanning ways. This is an exciting time to be an educator; our task is to take advantage of opportunities without remaining frozen, given fears and concerns. 


\section{References}

Anderson, T., \& Dron, J. (2011). Three generations of distance education pedagogy. The International Review of Research in Open and Distance Learning, 12(3), 80-97. Retrieved from http://www.irrodl.org/index.php/irrodl/article/view/89o

Banks, J., Au, K., Ball, A., Bell, P., Gordon, E., Gutierrez, K., Heath, S., et al. (2007). Learning in and out of school in diverse environments (Consensus Report). Learning in Informal and Formal Environment (LIFE) Center. Retrieved from http://www. life-slc.org/knowledge-base/report-learning-in-and-out-of-school-in-diverse-environments

Bryer, T. A., \& Chen, B. (2010). Using social networks in teaching public administration. In C. Wankel, (Ed.), Cutting-edge social media approaches to business education: Teaching with LinkedIn, Facebook, Twitter, Second Life, and Blogs (pp. 241-268). Charlotte, NC: Information Age Publishing.

Bryer, T. A. \& Zavattaro, S. (2011). Social media and public administration: Theoretical dimensions and introduction to symposium. Administrative Theory \& Praxis, 33(3).

Caruso, J., Smith, S., \& Salaway, G. (2009). The ECAR study of undergraduate students and information technology (Research Study). Boulder, CO: EDUCAUSE Center for Applied Research. Retrieved from http://www.educause.edu/erso9o6

Downes, S. (2007). An introduction to connective knowledge. Presented at the International Conference on Media, Knowledge \& Education-Exploring New Spaces, Relations and Dynamics in Digital Media Ecologies. Retrieved from http://www. downes.ca/post/33034

Facebook. (2011). Facebook statistics. Facebook. Retrieved July 22, 2011, from http:// www.facebook.com/press/info.php?statistics

Foulger, T. S., Ewbank, A. D., Kay, A., Popp, S. O., \& Carter, H. L. (2009). Moral spaces in MySpace: Preservice teachers' perspectives about ethical Issues in social networking. Journal of Research on Technology in Education, 42(1), 1-28. Retrieved from http://ezproxy.lib.ucf.edu/login?URL=http://search.ebscohost.com/login.aspx?d irect $=$ true\&db=eric\&AN=EJ856930\&site=ehost-live

Fountain, J. E. (2001). Building the virtual state: Information technology and institutional change. Washington, DC: Brookings Institution Press.

FSSE. (2010, July 25). Professors' use of technology in teaching. The Chronicle of Higher Education. Retrieved from http://chronicle.com/article/Professors-Useof $/ 123682 /$ ?sid=wc\&utm_source=wc\&utm_medium $=$ en

Glaser, B., \& Strauss, A. (1967). The discovery of grounded theory: Strategies for qualita- 
tive research. Chicago, IL.: Aldine Publishing.

Hanson, J. M., \& Sinclair, K. E. (2008). Social constructivist teaching Methods in Australian universities-- Reported uptake and perceived learning effects: A survey of lecturers. Higher Education Research and Development, 27(3), 169-186. Retrieved from http://ezproxy.lib.ucf.edu/login?URL=http://search.ebscohost.com/login. aspx?direct $=$ true\&db=eric\&AN=EJ803291\&site=ehost-live

Hew, K. F. (2011). Students' and teachers' use of Facebook. Computers in Human Behavior, 27(2), 662-676. doi:16/j.chb.2010.11.020

Hughes, G. (2009). Social software: New opportunities for challenging social inequalities in learning? Learning, Media and Technology, 34(4), 291-305. Retrieved from http://ezproxy.lib.ucf.edu/login?URL=http://search.ebscohost.com/login.aspx?d irect $=$ true $\& \mathrm{db}=$ eric\&AN=EJ870729\&site=ehost-live

Johnson, D. W., Johnson, R. T., \& Stanne, M. B. (2000, May). Cooperative learning methods: A meta-analysis. http://www.tablelearning.com. Retrieved from http:// www.tablelearning.com/uploads/File/EXHIBIT-B.pdf

Jonassen, D. H., Howland, J. L., Moore, J. L., \& Marra, R. M. (2003). Learning to solve problems with technology: A constructivist perspective. Upper Saddle Rover, NJ: Merrill Prentice Hall.

Kirschner, P. A., \& Karpinski, A. C. (2010). Facebook® and academic performance. Computers in Human Behavior, 26(6), 1237-1245. doi:16/j.chb.2010.03.024

Lave, J., \& Wenger, E. (1991). Situated learning: Legitimate peripheral participation. Cambridge University Press.

LinkedIn. (2011). LinkedIn about us. LinkedIn. Retrieved July 22, 2011, from http://press. linkedin.com/about/

Mazer, J. P, Murphy, R. E, \& Simonds, C. J. (2007). I'll see you on "Facebook": The effects of computer-mediated teacher self-disclosure on student motivation, affective learning, and classroom climate. Communication Education, 56(1).

Mazer, J. P., Murphy, Richard E., \& Simonds, Cheri J. (2009). The effects of teacher selfdisclosure via Facebook on teacher credibility. Learning, Media \& Technology, 34(2), 175-183.

Mix, K. K. (2010). Online social networking: Exploring the relationship between use of Web-based social technologies and community college student engagement. ProQuest, UMI Dissertations Publishing. Retrieved from http://ezproxy.lib.ucf.edu/ login?url=http://search.proquest.com/docview/847401829?accountid=10003 
Nellison. (2007, December 11). ECAR: Facebook as a teaching tool? Blog. Retrieved March 18, 2010, from http://nellison.blogspot.com/2007/12/ecar-facebook-as-teachingtool.html

Palmer, P. (2007). The courage to teach: Exploring the inner landscape of a teacher's life. San Francisco, CA: Jossey-Bass.

Rishel, N. (2011). Digitizing deliberation: Normative concerns for the use of social media in deliberative democracy. Administrative Theory \& Praxis, 33(3), 411-432.

Selwyn, N. (2009). Faceworking: Exploring students' education-related use of "Facebook." Learning, Media and Technology, 34(2), 157-174. Retrieved from http://ezproxy. lib.ucf.edu/login?URL=http://search.ebscohost.com/login.aspx?direct=true\&db $=$ eric $\& \mathrm{AN}=\mathrm{EJ} 856841 \&$ site $=$ ehost-live

Siemens, G. (2004). Connectivism: A learning theory for the digital age. elearnspace. Retrieved from http://www.elearnspace.org/Articles/connectivism.htm

Siemens, G. (2005). Connectivism: Learning as network-creation. elearnspace. Retrieved from http://www.elearnspace.org/Articles/networks.htm

Slavin, R. E. (1995). Cooperative learning: Theory, research, and practice (2nd ed.). Boston, MA: Allyn \& Bacon.

Smith, S., \& Borreson, J. (2010). ECAR study of undergraduate students and information technology (Research Study, Vol. 6). Boulder, CO: EDUCAUSE Center for Applied Research. Retrieved from http://www.educause.edu/Resources/ECARStudyofUndergraduateStuden/217333

Snowman, J., McCown, R., \& Biehler, F. (2009). Psychology applied to teaching. Boston, MA: Houghton Mifflin Co. Retrieved from http://www.worldcat.org/title/psychology-applied-to-teaching/oclc/228007807?page=citation

Twitter. (2011, March 14). Twitter blog: numbers. Retrieved July 22, 2011, from http:// blog.twitter.com/2011/03/numbers.html

U.S. Department of Education. (2010, March 5). National education technology plan 2010. U.S. Department of Education Website. Retrieved from http://www.ed.gov/technology/netp-2010/executive-summary

Vygotsky, L. S. (1978). Mind in society: The development of higher psychological processes. Harvard University Press.

YouTube. (2011). YouTube - broadcast yourself. Retrieved July 22, 2011, from http://www. youtube.com/t/press_statistics 


\section{Appendix}

\section{Interview Protocol}

1. What social media tools have you used in your classes?

2. What activities did you use with the social media tools?

3. What assessment strategies have you used to evluate theses activities?

4. What benefits do you perceive of using these social media tools in your classes?

5. What concerns do you perceive of using these social media tools in your classes?

6. Do you see any impacts of using social media on students' learning outcomes? Why?

7. What technologies do you see that instructors can use in teaching and learning in the future?

8. Do you have any suggestions regarding the issue of using social media for teach ing?

\section{Athabasca University $\mathbf{A}$}

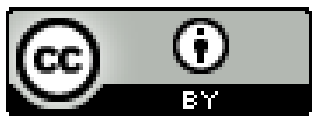

